\title{
Effective Methods to Improving Reading Skills in English Study
}

\author{
Zhanli Yang \\ Department of Pre-school Education \\ Hebei Vocational College of Foreign Languages \\ Qinhuangdao, China \\ e-mail: yzl200519751001@126.com
}

\begin{abstract}
The most common problem for an English learner is the difficulty in understanding the articles they are reading. Therefore, how to improve reading ability in learners draws more and more attention. The author of the paper has analyzed some common reading skills and put forwards some suggestions for the further improvement of English learners from personal experience, which may help to improve the learners' reading competence.
\end{abstract}

Keywords-Reading ability; vocabulary; word-building patterns; critical thinking; background knowledge; grammatical ability; good reading habbits

\section{INTRODUCTION}

As a result of China's move into a globalized community, English reading not only appears in exams but also exists in finding and obtaining information, entertainment or chatting online. For most learners of foreign languages, reading is the skill that creates most difficulty. Many learners try to find effective methods to improve their reading ability, but are still unsatisfied. How do we improve reading comprehension in English language study? In my opinion, the first steps are to identify the definition of reading and the types of reading skills required, then based on this understanding, look for effective methods accordingly..

Generally speaking, reading is about understanding written texts. But understanding is not simple looking. It is a complex activity that involves both perception and thought. It consists of two related processes: word recognition and comprehension. Word recognition refers to the process of perceiving how written symbols correspond to the spoken language. Comprehension is the process of making sense of words, sentences and connected text.

One of the most obvious, but often unnoticed facts about reading is that there are different types of reading skills. They mainly include skimming, scanning, extensive and intensive reading. Skimming means reading rapidly for the main idea; Scanning is to read rapidly to find a specific piece of information; Extensive reading means reading a long text, often for pleasure with emphasis on its overall meaning; Intensive reading means reading a short text for details. In China most learners studying English often feel that if they don't understand every word they are not completing the exercise. Obviously that's wrong; you can't make big improvements without the most appropriate reading style for the function. Therefore identifying the reading style required in a specific reading situation should be decided prior to commencing reading.

We cannot talk about effective reading methods until we understand this point.

\section{SOLUTIONS FOR IMPROVING ENGLISH READING ABILITY}

\section{A. Enlarged vocabulary improves comprehension}

Many teachers agree that vocabulary is the key to learning English well. The larger your vocabulary, the more effectively you can learn. This doesn't mean you should take a dictionary wherever you go. Enlarging vocabulary requires accumulating and using words on a daily basis. Easy methods to increase vocabulary as a part of daily life include reading everyday, using modern materials such as English language newspapers, eg China Daily or the New York Times. New words and expressions can be researched in a Chinese-English dictionary. Writing the new words and phrases in a notebook and creating new sentences with them ensures practice and creates understanding of usage. Review of new words is important for memory retention. When reviewing the new words, remember their usage in the context. There may be difficulties in the beginning, but persistence will increase understanding and reading pleasure. .

\section{B. Improve comprehension by guess Guessing the meaning from the context.}

The context helps leaners to guess the unknown vocabulary. Firstly the reader can refer to the immediate context and then to the wider context in which a word is found. The immediate context is the sentence in which a word is found and sometimes the sentences immediately before and after this.The wider context can include other sentences and even other paragraphs in a text. Both forms of context can often provide important information which help in deciding the meaning of unfamiliar words.

Context provides readers with numerous clues to deduce the unknown words. The main contextual clues include definition, synonym, antonym, and example and cause-effect relation. The signal words of definition include be, be called, be termed, mean, can be defined as, refer to, be known as, signify, denote, etc. The signal punctuations are: brackets, dash, 
comma, etc. Synonym signals include that is, that is to say, in other words. Antonym signals are although, while, whereas, however, but, yet, on the contrary, in contrast. The signal words of example are such as, unlike, for instance, a case in point, for example, etc. The signal words of cause and effect relation are because, because of, as, since, for.

\section{Guessing the meaning from word-building.}

In English, by adding a prefix or suffix, or both a prefix and a suffix to a stem word, numerous words are created.

For example:

Adding a prefix

Nod your head to show agreement; shake your head to show disagreement. (Adding "dis-"before "agreement" to form "disagreement")

\section{Adding a suffix}

You should raise the awareness of non-verbal communication signals in business negotiation. (Adding "ion" after communicate to form "communication")

Adding both a prefix and a suffix at the same time

Unfortunately he doesn't seem to be so quick to reply to comments when people criticize him. (Adding "un-"before and "-ate" plus "-ly" after "fortune" to form "unfortunately")

Knowledge about stems, prefixes and suffixes would be of great help for readers to guess the meaning of unknown words.

\section{Improve your comprehension by recognizing patterns.}

Historically, humans have survived by identifying patterns. Scientists say that it is human nature to look for patterns in what we see. Our brains are always trying to make sense of the world around us, trying to fit everything into some kind of recognizable shape that has meaning for us.

There are four common patterns in a text. The first pattern is a listing related ideas or examples. In this pattern, the writer's main idea is stated in the form of a generalization, followed by a list of supporting details. Signal words for this pattern include: such as a few, other(s), another, first, second, third, several, many, in addition, numerous. The second pattern is sequence. In this pattern, the writer's main ideas include a series events or steps that follow one after another. The third is comparison and contrast. In this pattern, the writer's main idea explains similarities or differences, with signaling words including; like, both, similarly, however, but, unlike, while, and so on. The final pattern is cause-effect. When the main idea is developed by describing one event or action causing another, the cause-effect pattern is demonstrated. Causes and effects are part of daily life, therefore, this pattern is found very often in history books, science texts, and novels.

\section{Distinguishing facts from opinion}

To make a distinction between facts and opinions will help achieve a deeper level of understanding in our reading.

Facts can be used by a writer as a basis for persuading the readers that his idea is right, they are usually objective descriptions or statements; Opinions are often stated to express the author's attitudes or feeling about things, and so are subjective evaluations or predictions from both the character and the author. For example, "There are specific medical conditions that are known to benefit from certain vitamin supplementation" is a fact, while "Points to remember when selecting vitamin supplements: XYZ Vitamins are the best." is an opinion. Another example, "Research indicates that most of the vitamins you get from the food you eat are better than those contained in the pills" is a fact, while "If you feel that you could be lacking in certain vitamins and minerals, it may be better to consider changing vitamin tablets to XYZ brand." is an opinion.

In general, facts are directly related to the development of the plot in a novel while opinions provide the author's and character's reflections.

\section{E. Clarify the main idea of a passage.}

- Searching for the main idea.

The main idea of a piece of writing is the central point the author wants to make. It is stated in a topic sentence, which sets the thesis, but also the tone, voice and style of the writing. Generally speaking, in the majority of articles written for English readers it is located in the beginning of the writing, but may be re-iterated in the body and conclusion of the piece. Other language forms may change the position for the expression of the main idea. In addition, in many cases, the main idea is not always clearly stated. It is more difficult to identify a main idea when it is inferred or implied. Summarising and restating the information in the passage helps decipher the main idea.

Summarizing is taking larger selections of text and reducing them to their bare essentials: the gist, the key ideas, and the main points that are worth nothing and remembering. It's the distillation, condensation or reduction of a larger work into its primary notions.

Summaries capture the main ideas and the crucial details. Summarizing mainly includes noting key words, sentences and short passages.

\section{- Critical thinking.}

Experience demonstrates that to gain a better understanding of the text it is important to ask questions.

Critical thinking is a good method to help gain better understanding of the text. Few writers ever directly tell you what to think, they try to give enough data to allow readers to reach reasoned conclusion.

The purpose of critical thinking in reading is to involve the reader in the reading activity more thoroughly.

\section{F. Using the SQ3R strategy}

SQ3R is a useful and important method in reading to absorb written information. It helps build a good construct of the subject, creating a framework for appropriate insertion of facts. In addition, SQ3R enables readers to set study goals and prompts the use of revision techniques.

The acronym SQ3R stands for the five sequential techniques readers should use to read a book. Scan the "S" means a short survey, "Q" is question; the " $3 \mathrm{R}$ " are read, recall 
and review. Survey means to scan the contents, introduction, and summaries to pick up a preliminary overview of the text. Question means note any questions on the subject that come to mind, or particularly interest you. The first "R" means read useful sections in detail, with attention to relevant points; the second $\mathrm{R}$ requires the reader to remember important sections once they are read, isolating the core facts or the essential processes behind the subject, and then assess how other information fits. The third $\mathrm{R}$ asks the reader to review the reading rev. This review can be done by re-reading the document, by expanding notes, or by discussing the material with other readers. A particularly effective method of reviewing information is to teach it to someone else.

By using SQ3R to actively read a document, the maximum benefit is gained from the reading time.

\section{G. Activate background knowledge}

One of the biggest predictors of reading comprehension is background knowledge. Readers comprehend better when they actively think about and apply their knowledge of the topic and their own experiences.

Background knowledge can be used to increase reading comprehension, especially when dealing with unfamiliar topics. Here are some suggestions to apply background knowledge whenever needed.

Before reading, consider any related knowledge of the topic. While reading, activate other memories, personal experiences and any other kinds of information related to the details of the reading material.

After reading, research further at the library or on the Internet to find answers to the remaining questions.

Activating background knowledge is an important reading method for better comprehension.

\section{H. Improve comprehension by improving grammatical understanding}

Grammar is also the essential and, some think, the most difficult part of English language study. It can be many students' weakest area

English grammar is an important and useful tool in reading. It is a combination of the phonics and holistic argument. In order to understand the whole we must see the parts. Grammar is an important tool especially for weak readers to help them to understand ideas. It is the mathematics of literature and composition.

Therefore, it is essential to study grammar and have a strong grammatical base. Grammar can be learned in small steps, and requires some general practice. Learn the basics of one grammar point, then move on to another. When readers are comfortable with the basics, they can move forward to study the details. Grammatical skills improve comprehension, and are worth studying.

\section{Improve comprehension by understanding references and making inferences.}

When a listener overhears a part of a conversation and tries to imagine what it was about is a common use of making inferences. Sometimes the topic of a text may not be stated anywhere directly, in the reading, making the look for clues and try to guess what the passage is about. The authors of novels, stories or plays often do not explain everything about characters or situations. The reader must infer the author's meaning from the descriptions or the dialogues.

For example: The underlined (references) in the following passage can help us to infer that "it" is a small animal.

I found it in the middle of the sidewalk on my way home from school one spring morning. It was very tiny and it was hardly breathing when I picked it up. I fed it raw meat and other treats for several weeks. Soon, it became strong and started to hop around.

\section{J. Improve comprehension by forming good reading habits.}

Most people wish they read more, because it can help increase knowledge and be more successful in a variety of fields. The following suggestions can help strengthen your reading ability. Always have reading material close by bathroom, briefcase and bed;.

Set a reading goal. Determine how much time can be spent on reading, or how many books to read over time. Reading groups and books clubs can support reading goals and provide discussion groups for deeper understanding.

Reading involves specific skills sets knowledge and common sense. By analyzing and generalising the skills in the process of reading, these skills and methods can be transferred easily to struggling readers.

\section{CONCLUSION}

Most of the reading skills, such as how to deal with the unfamiliar words, how to find the main idea, how to critically read, and how to comprehend better by various kinds of resources can be developed by following the techniques mentioned above.

\section{REFERENCE:}

[1] David Numan, Language Teaching Methodology P.70 Lexican Relationship.

[2] Gibbon , H. (2000) How to Read .Privitization Yearbook, London: Thomson, Financial.

[3] Anderson, R,C, Spiro, R.J., \& Montague,W.E.(Eds).(1997).Schooling and the Acquisition of Knowledge. Hillsdale:35.

[4] Anderson, R.c.,Osborn,J.,\& Tierney,R.J.(Eds.).(1984).Learning to read in American schools: Basal Readers and Contents Texts.

[5] Allington, R.L.'How policy and Regulation Influence Instruction For At-risk Learners: Why Poor readers Rarely Comprehend Well and Probably Never Will”. In L.Idol, \& B. F. Jones (Eds). (1991) Educational values and Cognitive Instruction : Implication for Reforms. Hills dale. NJ: Erlbaum. 